\title{
Toward an alternative dialogue between the social and natural sciences
}

\author{
Johannes Persson $^{1}$, Alf Hornborg ${ }^{2}$, Lennart Olsson $^{3}$ and Henrik Thorén ${ }^{3,4}$
}

\begin{abstract}
Interdisciplinary research within the field of sustainability studies often faces incompatible ontological assumptions deriving from natural and social sciences. The importance of this fact is often underrated and sometimes leads to the wrong strategies. We distinguish between two broad approaches in interdisciplinarity: unificationism and pluralism. Unificationism seeks unification and perceives disciplinary boundaries as conventional, representing no long-term obstacle to progress, whereas pluralism emphasizes more ephemeral and transient interdisciplinary connections and underscores the autonomy of the disciplines with respect to one another. Both approaches have their merits and pitfalls. Unification runs the risk of scientific imperialism, while pluralism can result in insurmountable barriers between disciplines. We made a comparison of eight distinct interdisciplinary attempts at integration of knowledge across social and natural sciences. The comparison was carried out as four pairwise comparisons: environmental economics versus ecological economics, environmental history versus historical ecology, resilience theory versus political ecology, and socio-biology versus actornetwork theory. We conclude by showing that none of these prominent eight interdisciplinary fields in and of itself manages to provide, in a satisfactory way, such an integrated understanding of sustainability. We argue for pluralism and advocate complex ways of articulating divergent ontological assumptions. This is not equivalent to pursuing knowledge unification either through scientific imperialism or by catering to the requirements of narrow practical utility. It means prioritizing interdisciplinary integration by simultaneously acknowledging the role of societal and natural factors in accounting for sustainability issues.
\end{abstract}

Key Words: interdisciplinarity; ontology; pluralism; scientific imperialism; sustainability; unificationism

\section{INTRODUCTION}

The integration of scientific disciplines, and of science and society at large, is a widely accepted goal of sustainability science (Jerneck et al. 2011). The reason is simple: Sustainability problems are often regarded as wicked, crosscutting problems that require those who address them to understand the limitations of, and to some extent overcome, the boundaries of individual disciplines (Fischhoff 2016). Nonetheless, interdisciplinary integration, regardless of whether the aim is to establish a new discipline or to keep the involved disciplines structurally intact, is difficult to achieve for any number of reasons, including, for example, uncertain outcomes and institutional barriers (see, e.g., Wolman 1977, Klein 1990, Hansson 1999, Bammer 2013). There are other problems, too, which arise more from the substance of the involved disciplines: differences in ontology and epistemology that make interdisciplinary connections and communication difficult to establish (e.g., Persson et al. 2018). Jerneck et al. (2011:78) point out that "[d]ifferences in ontology and epistemology constitute one of the main obstacles to the integration of knowledge across scientific disciplines." Sustainability science is an interesting case in point, as the aim is typically to integrate knowledge from natural and social science disciplines, a form of integration that can be expected to be particularly difficult.

Making analytical use of a distinction between pluralist and unificationist attitudes to integration, we discuss several concrete attempts to cross the natural/social science divide. Because we do not think it realistic to suppose, in general, that a discipline as a whole adapts its foundation in the face of interdisciplinary challenges, we argue for a pluralistic attitude, an alternative dialogue.

\section{UNIFICATIONIST AND PLURALIST ATTITUDES TO INTERDISCIPLINARITY}

The notion of integration is not particularly clear (e.g., O'Rourke et al. 2016). We believe it is helpful to distinguish between two approaches to interdisciplinary integration, approaches we label "unificationism" and "pluralism." The unity of science, the role of unification, and the role of plurality and pluralism are longstanding and complex issues in the philosophy of science (see, e.g., Cat 2017). The ideal of unificationism in particular has had a considerable impact on science theory. Whether there is one or several scientific methods, one or several kinds of scientific explanation, a fixed set of epistemic values, and so forth, was discussed at length by some of the best-known philosophers of science of the 20th century. The writings of Karl Popper (1952), Carl Hempel (1965), and William Dray (1957) on the nature of explanation are some of the many instructive examples, and their work can be traced back to seminal works by J. S. Mill (2002/1843). The influence of these discussions of science and scientific attitudes should not be underrated. Unfortunately, however, the positions and arguments are often misrepresented in influential textbooks on method for the special sciences today (for an account of the distortion of positivism, see e.g., Shadish [1995] and Persson [2010]). An exhaustive exposition is beyond our scope. Instead, we draw on a general understanding of the unificationist and pluralist approaches, or rather their implications.

Confining our attention to disciplines, we can say that the unificationist seeks, or emphasizes, unification and perceives disciplinary boundaries as conventional, representing no long-term obstacle to progress. By contrast, the pluralist emphasizes more ephemeral and transient interdisciplinary connections and 
stresses the autonomy of the disciplines with respect to one another.

It is a fact that different disciplines operate on different principles, using different theories with different ontological claims, concepts, models, and methods, to approach their subject matter; unificationism, in any of these respects, builds on abstraction or idealization if it is conceived of as a descriptive thesis (see also Hacking 1983). Some of these differences are explicit and clear. Others reside in tacit assumptions, embedded in practices and conventions. Some reflect deeply held beliefs and express the core of the discipline, whereas others are peripheral and up for revision (e.g., Persson et al. 2018). Unificationism and pluralism regarding sustainability science or any other science will only come into clear conflict when one says what is to be unified or pluralized ${ }^{[1]}$ Unity in one aspect of inquiry may provide enough rigidity to allow for plurality in another. Indeed, influential perspectives in science and technology studies strive to combine the two. Star and Griesemer's (1989) notion of a "boundary object" postulates the presence of an object flexible enough to be adapted to the particular needs of actors in different contexts, but rigid enough to allow for communication. It can be seen, then, that there might be unificationism and pluralism with regard to different things. We might, for instance, be pluralists about all or some of the following: concepts, ontology, explanations, virtues, goals, methods, models, and kinds of representations. What is general about the framework of pluralism, or pluralisms, may simply be that it "rejects the ideal of consensus in cognitive, evaluative and practical matters, against pure skepticism (nothing goes) or indifferentism (anything goes), including a defense of preferential and contextual rationality that notes the role of contextual rational commitments" (Cat 2017).

Recent discussions of scientific imperialism highlight the difference between unificationism and pluralism, and the implications of that difference, particularly in relation to ontology and ontological unification (Mäki 2009, 2013, Kuorikoski and Lehtinen 2010). Uskali Mäki (2009, 2013) stresses that an acceptable, or tolerable, imperialism needs to achieve ontological unification:

\begin{abstract}
The pursuit of unification in its ontological mode is a legitimate process of discovery of the extent to which there is unity in the world itself: the extent to which parts of the world are made of similar components, governed by similar laws, or generated by similar causal mechanisms, and so on. The only way to find out about the limits to this ontic unity is to try to unify as far as possible, regardless of whether disciplinary boundaries are being crossed. (Mäki 2013:336)
\end{abstract}

Broadly speaking, for the ontological unificationist, imperialist infringements between disciplines are admissible if there is some underlying ontological similarity between items in the domains of the disciplines. In other words, ontological differences between disciplinary domains are perceived as blocking integration by leading to a proliferation, among the disciplines, of theories and explanatory frameworks. For the unificationist, genuine ontological differences between disciplines constitute a hard boundary to integration. If the ontologies of two disciplines cannot be reconciled, there is no integration to be had. In this respect, the bar for successful integration is rather high. Ontological unification represents a substantive achievement. At the same time, the risks appear low because, although disciplinary borders might have to be reworked when reality reasserts itself somewhere down the line, the borders themselves were never thought of as serving any crucial function. The risks involved are borne by individual scientists who might work on unrealistic projects or theories. However, science just is risky in this respect, and so it should be, the unificationist would claim. Imagine someone like E. O. Wilson launching a bold project in sociobiology. The project might involve significant risks for the researchers and stakeholders who invest time and resources in it; it might turn out to be a dead end. However, claims the unificationist, the fact that it threatens contemporary disciplinary boundaries is not among the major risks. The scientific value involved in upholding disciplinary boundaries is dependent on whether those boundaries can be expanded without ontological conflict.

In real academic life, of course, imperialist infringements can be difficult to handle. It has been argued in interdisciplinary water research, for instance, that the social sciences typically take on a subordinate or service role in putatively interdisciplinary constellations. The supposed direction and value of imperialism is not normally open to discussion, and this leads to dissatisfaction and to more agonistic modes of interdisciplinary working (Krueger et al. 2016; see also Seidl and Barthel 2017).

For the justification of pluralism, on the other hand, as opposed to skepticism (nothing goes) or indifferentism (anything goes), ontology is less important (e.g., Kellert et al. 2006). There are worthwhile and important interdisciplinary connections to be made even in the absence of ontological unification. The bar for integration is thus set lower in a sense, but at the same time, the scientific risks are substantial. An important difference between unificationists and pluralists at the disciplinary level is that the latter perceive disciplines as vehicles of scientific progress. Crossing disciplinary boundaries risks disrupting this basic structure by, for instance, introducing new anomalies, and thus it may derail an otherwise progressive scientific venture (see also Persson et al. 2018).

The proposed distinction does not exhaust all possible interpretations of unificationism and pluralism, not by a long shot. It is instead meant to highlight what we see as important differences in the attitudes scientists can bring to their interdisciplinary collaborations, differences ultimately affecting the way outcomes are evaluated and weighed and the way risks are perceived and gauged. We will pay special attention to ontological unification and pluralism.

\section{DIVERGENT ONTOLOGICAL ASSUMPTIONS AMONG NATURAL AND SOCIAL SCIENTISTS}

Today, the ambition to dissolve the ontological differences between social and natural phenomena is common. However, it is evident that there is not one, but several typical differences in the ontological attitudes of social and natural scientists, differences that sometimes also exist within social and natural sciences. It is important to pay special attention to these when one is trying to determine whether to adopt a unificationist or pluralist strategy in sustainability science. 
First, society and nature are intertwined in empirical reality but have aspects that should be kept analytically, and perhaps ontologically, distinct. The primary distinction, as traditionally made, can be expressed as that between symbolic and presymbolic phenomena or study objects. Symbolic phenomena are products of uniquely human processes of negotiating meanings. They are contingent on human subjectivity but are causally influential components of social-ecological realities. The human sciences have developed analytical tools and concepts for dealing with human subjectivity, e.g., culture and semiotics, whereas natural sciences generally have no need for such concepts.

Second, social and natural scientists tend to approach questions of truth and objective reality differently. Many social scientists emphasize that all human representations of reality are contingent constructions, and some would even argue that it is meaningless to speak of an objective reality. Natural scientists, on the other hand, often visualize their research results and conclusions as accurate, or approximately accurate, representations of a posited reality. The difference between constructivism and realism tends to lead to different positions on the relation between the researcher and his or her study object: Whereas constructivism suggests participation and involvement, realism suggests objectivism and detachment. A reasonable compromise between these two positions, it has often been claimed, is to insist that there is an objectively existing reality to which our empirical observations ultimately refer but to also acknowledge that any attempt to represent it will be partial, situated, and provisional. This approximates several modern versions of realism, including the position known as "critical realism" (Bhaskar 1997/1975).

Third, although both natural and social scientists tend to suffer from the illusion that bounded objects can be exhaustively accounted for by tracing their internal constitution, without regard for the external relations and flows that sustain them, this fallacy has different implications for natural and social sciences. An example from the natural sciences would be an approach to biological organisms that considers the careful study of their anatomy or genetics a sufficient account of the existence of these organisms. A rival perspective would stress the coevolutionary processes and ecological relations, including "ecosemiotic" communication (see von Uexküll 2010), in which every organism is embedded. A similar duality of perspectives can be observed in social scientists' understanding of technology. One approach would be to consider the designs of engineering sufficient to account for the appearance of a given technology, whereas another would emphasize the global exchange rates, market conditions, and flows of matter/energy that keep it running. This duality of perspectives, highlighting interior design versus fields of external relations, can be referred to as "reification" versus "relationism." Relationist understandings of the emergent properties of natural and social phenomena have been presented in various forms of systems theory and field theory.

This trio of differences between and within natural and social sciences pervades mainstream Western knowledge production, and forerunners of the three contrasts have been acknowledged since at least the Enlightenment. There is a widespread tendency to underestimate the role, and efficacy, of symbolic phenomena in organizing material reality through the generation of fields of relations, which, ultimately, are subjectively constituted even if they manifest themselves in tangible, objectively existing conditions such as landscapes, climate, or technologies. In grasping how the subjective and the objective are interfused, while keeping the two kinds of phenomena analytically distinct, we are able to identify the difference between technology and magic. Both involve the delegation of agency to artifacts, but whereas the agency of technology is contingent merely on the physical properties of the artifacts themselves, magic can be defined as a social delegation of agency to artifacts where that agency is contingent on the subjective perceptions of humans. A simple example of this distinction is the difference between the agency of keys and the agency of coins, before the invention of the slot machine! The capacity of a coin to open doors is generally contingent on the perceptions of the doorman, whereas the capacity of a key to do so is contingent on its physical shape alone.

The distinction between aspects of reality that depend on human perceptions and aspects that do not has been emphasized by, among others, Roy Bhaskar (1997/1975), who usefully distinguishes between "intransitive" and "transitive" aspects of reality. An important challenge for interdisciplinary research is to systematically explore how Bhaskar's intransitive-transitive distinction intersects with the natural-social distinction. The two distinctions obviously do not coincide completely. They appear to have different implications depending on whether we are considering processes over time or structural conditions at a particular point in time. For example, human perceptions have played a significant role in the processes generating climate change, but the state of the global climate at a given point in time is a nonnegotiable, intransitive reality. Many aspects of power inequalities, including purchasing power, technological capacity, and military strength, are intransitive manifestations of social relations with an indisputably transitive dimension. To neglect to consider these differences in an integrative attempt to unify natural and social sciences is to run the risk of failed unificationism.

\section{EIGHT ATTEMPTS TO INTEGRATE KNOWLEDGE ACROSS THE SOCIAL AND NATURAL WORLDS}

Although they are not intended to dismiss wholesale the important contributions of interdisciplinary fields such as ecological economics or political ecology (PE), the subsequent brief discussions of eight attempts to integrate knowledge across the social and natural worlds illustrate the way in which the ontological assumptions in natural and social sciences constrain attempts to integrate knowledge from the two domains. In view of the indisputably "socio-natural" character of the reality in which we are immersed, a major challenge for all research is to cultivate a capacity to acknowledge the combined and simultaneous operation of phenomena and regularities deriving from both fields. This should not be a matter of positing a "flat ontology" in which social, biotic, and abiotic phenomena are all equivalent "actants," as proposed within actor-network theory (ANT). All we are required to do is emphasize and acknowledge the distinctive differences between social and natural phenomena (Hornborg 2017).

We summarize the eight discussions in Table 1. We conclude with recommendations for an alternative approach that helps to facilitate the dialogue between the natural and social sciences (see also Olsson and Jerneck 2018). 
Table 1. Frequent barriers to integration and communication between social and natural scientists.

\begin{tabular}{|c|c|c|}
\hline Ontological Assumptions & Natural Science & Social Science \\
\hline $\begin{array}{l}\text { Modes of knowledge production (ontological } \\
\text { approach) }\end{array}$ & $\begin{array}{l}\text { Emphasizes representation of an independent } \\
\text { and objective reality }\end{array}$ & $\begin{array}{l}\text { Emphasizes construction of a contingent } \\
\text { environment }\end{array}$ \\
\hline $\begin{array}{l}\text { Character of phenomena to be explained (study } \\
\text { objects) }\end{array}$ & Nonsymbolic & Symbolic \\
\hline Researcher's role & Detached from object of study & Embedded and participatory \\
\hline Examples of failed attempts at unification & $\begin{array}{l}\text { Natural science accounts of socio-natural } \\
\text { phenomena: resilience theory, ecological } \\
\text { economics, historical ecology, and socio-biology }\end{array}$ & $\begin{array}{l}\text { Social science accounts of socio-natural } \\
\text { phenomena: political ecology, environmental } \\
\text { economics, environmental history, and actor- } \\
\text { network theory }\end{array}$ \\
\hline
\end{tabular}

\section{Resilience theory versus political ecology}

Use of the concept of resilience has exploded in recent years, in policy as well as in science, and not least in policy-relevant science. We restrict our analysis to resilience theory as it emerges from ecology, but it is also our ambition to incorporate social phenomena in the same theoretical realm (e.g., Walker and Salt 2012). Resilience theory is essentially an attempt to apply perspectives from systems ecology to so-called coupled socialecological systems. It revolves around explaining change and adaptation in complex adaptive systems, a class of entities assumed to include ecosystems but also the aforementioned social-ecological systems and social systems such as economies or organizations (see, e.g., Gunderson and Holling 2002). A central idea is that by keeping systems stable, e.g., by suppressing outbreaks of budworms in a forest, we may imperceptibly erode the resilience of the system. This is a classic example of the use of the resilience concept, see Ludwig et al. (1978). In it, the system becomes sensitive to disturbances it would otherwise have absorbed (Berkes and Folke 1998, Gunderson and Holling 2002). In the language preferred by resilience theorists, the adaptive capacity of the system decreases in the budworm example. Resilience theorists see this dynamic played out in a wide range of different systems. Generally speaking, resilience theory relies on explanations of change, adaptation, and collapse couched in terms of systemic causes, and it is a foundational assumption of the framework that the ontological category "complex adaptive system" is broadly applicable.

This is a legitimate issue to examine in connection with natural ecosystems, but it becomes problematic when it is applied to social organization. Although it builds on the incontrovertible observation that the regularities and trajectories of social and natural systems are intertwined, resilience theory resorts almost exclusively to models from natural science to understand the logic of such complex phenomena. A predictable consequence of this theoretical one-sidedness is that phenomena peculiar to social systems, such as power asymmetries and cultural ideologies, are excluded from, or trivialized in, the analysis.

What we see is thus a unificationist approach: one assuming that the relevant parts of the world are made of similar components, governed by similar laws, and generated by similar causal mechanisms. It is an imperialistic infringement, and accordingly, and unsurprisingly, social scientists object that resilience theory ignores the most important drivers of social-ecological change (Hornborg 2009, 2013, Walker and Cooper 2011, Olsson et al. 2015, Watts 2015).
PE also attempts to integrate knowledge across the social and natural sciences. Rooted in political economy, PE is best described less as a single body of theory, and more as a loosely organized approach comprising broadly similar perspectives and concerns. It developed in reaction to what was perceived as narrow views on human-environmental relations in cultural ecology and other traditions, particularly in terms of adaptationist and deterministic models of environmental change and the scant attention paid in them to power (Robbins 2004, Blaikie 2008, Watts 2015).

As its name indicates, $\mathrm{PE}$ is conceived as an explicit alternative to traditional ("apolitical") ecology (Robbins 2004); it takes societal and ecological processes to be fundamentally intertwined. By focusing on the way political and economic factors at several levels, and on differing scales, shape and are shaped by the environment, PE differs from conventional ecological perspectives by not only politicizing environmental issues, but also "ecologizing" political processes (Bryant and Bailey 1997, Hornborg et al. 2007). As most of its proponents have a background in social sciences such as geography, anthropology, and sociology, PE has been criticized for promoting "politics without ecology" (Vayda and Walters 1999:168). Thus, ecologists based in the natural sciences have complained that although PE does offer insights into the way economic and political factors shape processes of environmental degradation, PE analyses often overlook the role of biophysical, nonhuman factors.

The case of PE may therefore represent scientific imperialism originating from a social science point of view. Again, consideration of the ontological components is important. The omission of biophysical factors is indicative of an attempt to ontologically unify the field of PE with traditional social science.

\section{Environmental economics versus ecological economics}

It is also useful to contrast environmental economics with ecological economics, as they approach the same topic, i.e., the relationship between the natural environment and human economic activity, but from different directions. Environmental economics represents the attempt of mainstream neoclassical economics to incorporate concerns about environmental degradation. In economic terms, the idea is to internalize "externalities." This is carried out primarily by putting a price on nature, that is, by calculating the economic value of various aspects of the natural environment in terms of what people would be willing to pay for their preservation. In this way, it is 
hoped that the environmental consequences of economic activity can be included in cost-benefit analyses. Environmental problems are fundamentally perceived as solvable by introducing incentives, i.e., subsidies, and disincentives, i.e., taxes and penalties. Environmental economics is often combined with a strong belief in self-organizing markets, an idea compatible with the complex adaptive systems underlying resilience theory (Olsson et. al 2015).

Ecological economics, on the other hand, attempts to transcend conventional neoclassical economics by integrating natural science perspectives such as those from physics and ecology with knowledge of the operation of human economies. Indeed, it is often categorized as "heterodox" economics. There is an obvious tension between ecological and environmental economics. At the ontological level, ecological economics claims that the earth's life support systems are all-encompassing, but social and economic systems are subordinate; whereas in environmental economics, society, the economy, and the environment are all interrelated systems at the same level. If environmental economics underlines the word economics, in the sense that it is an expansion of conventional or orthodox (neoclassical) economics, ecological economics underlines the word ecological.

The relationship between economics and ecology as disciplines has interesting roots (O'Neill 2004). In his essay "Scientism and the Study of Society," Hayek (1942) argues very strongly against scientific objectivism, represented by natural science. In his view, social objects are constituted by beliefs, ideas, and values about the natural world rather than their physical aspects, such as chemical, physical, or biological properties. The objects of economic activity cannot be defined in objective terms; they can only be fixed with reference to human purpose. Commodities, economic goods, food, and money must be defined in terms of the views people hold about such things, not physical terms (Hayek 1942). In contrast to this, the ecological economists find it reasonable to acknowledge that physical reality, such as access to energy, decisively influences the trajectories of economic processes (Martinez-Alier 1987, Hall and Klitgaard 2011, Ayres 2016). A recurrent problem in ecological economics, however, is the claim that money prices should reflect biophysical metrics such as embodied energy (Odum 1988) or "ecosystem services" (Costanza et al. 1997). The ontological claims of natural science are given priority. Very few scholars provide a truly interdisciplinary perspective in which economics and physics are respected as distinct but interacting aspects of reality. Nicholas Georgescu-Roegen (1971), an economist with a profound grasp of physics who is consistently critical not only of mainstream economists' ignorance of physics, but also of the ambition of some ecological economists (Costanza 1980, Odum 1988) to reduce economics to physics, is a rare exception. For social scientists, the urge to theorize societies as variations on natural systems (e.g., Odum 1971, Ayres 2016) often appears to ignore fundamental analytical tools of social science such as the concepts of culture and power. Social scientists remain unconvinced that distinctive features of social systems, such as their cultural and political dimensions, can be reduced or analyzed away using natural principles such as the laws of thermodynamics.

Ecological economics is perhaps the most promising of our eight examples of integration, but it comes at a cost, reducing society to economics and nature to stock and flow models. In other words, this may be a case where unificationism can be reasonably expected to eventually succeed and where, with hindsight, the imperialistic infringement can be tolerated, i.e., treated as warranted.

\section{Environmental history versus historical ecology}

By and large, environmental historians tend to focus on human perceptions of their natural environment, whether those perceptions represent more or less passive understandings of biophysical conditions or are constructions actively contributing to practices that generate environmental change. This is evident in the extent to which they rely on historical sources such as archival materials and other written texts (e.g., Hughes 2001, Richards 2003, Radkau 2008). Although the field belongs methodologically within the human sciences, it aims to incorporate the material reality of biophysical processes, as can be seen particularly in discussions of more recent environmental history (e.g., McNeill 2000, McNeill and Engelke 2016). The recurrent challenge for environmental history is to theoretically integrate the agency of cultural ideas and political and economic power structures, on the one hand, with empirical environmental change, on the other (Hornborg 2010).

Environmental historians, then, seem to be optimists (cf. "Popperian optimism" in Persson et al. [2018]) about the possibility of overcoming ontological boundaries and barriers. That is not quite the same thing as having a program for how such integration should succeed. There is no evidence, as far as we can see, that they are aware that integration requires a unified ontology.

In the past, historical ecology has approached humanenvironmental relations from the opposite direction, taking as its point of departure the natural science methods employed by archaeology. The field has focused on the discovery of evidence of anthropogenic impacts on the environment in the records assembled by sciences such as paleobotany, paleozoology, and paleoclimatology (e.g., Crumley 1994, Redman 1999, Balée and Erickson 2006). Although the ambition is to integrate C. P. Snow's "two cultures" (cf. Crumley 1994), the focus has inexorably gravitated toward objective, biophysical evidence. At the same time, human perceptions have largely become topics of speculation. Again, the choice of ontological outlook, reflected in the development of a methodology, tends to relegate the interdisciplinary study of the history of human-environmental relations either to the natural science or to the social science side. In that way, the integrative character of historical ecology is downplayed.

\section{Socio-biology versus actor-network theory}

Socio-biology, established in the 1970 s more or less singlehandedly by E. O. Wilson with the publication of his book of the same title (Wilson 1975), is often treated as a textbook case of scientific imperialism. One can see why: As a field of inquiry, it is based on the assumption that human behavior can be exhaustively explained in evolutionary terms. Everything is an adaptation to something: Love, murder, rape, and so on, exist because, at one time or another, some form of evolutionary benefit attached to those behaviors. The idea was immediately and fiercely criticized. Marshall Sahlins (1977) quickly dismissed sociobiology on grounds of its complete ignorance of the way in which social and cultural systems can override and indeed negate the 
apparent implications of biology. Another early, and very influential, critique was that of Stephen J. Gould and Richard Lewontin (1979). They point out that highly functionally integrated entities, such as biological organisms, develop under a range of different, often contingent, constraints that limit their possibilities. For instance, pigs would greatly benefit from the possession of wings, but their general body plan prohibits such development. Mary Midgley takes socio-biology to be an imperialist infringement on the social sciences because its proponents, like E. O. Wilson himself, often sought to "take over the social sciences" (Midgley 1984b:159; see also Midgley 1984a, Dupré 2001).

In its bold attempts to obviate the contributions of social science, or reduce them to biology, early socio-biology, at least, does appear to be a case of scientific imperialism. Although contemporary socio-biologists still try to explain human behavior and social organization through biological evolution, they also point out that objections like those mentioned previously were often based on misrepresentations of the discipline (Alcock 2017). The empirical fact that affluent families tend to have fewer children than families on low incomes is now explained in terms of evolutionary selection mechanisms (Alvergne and Lummaa 2014). Dysfunctional leadership in public and private organizations is explained as a gene-culture coevolution by Vreja et al. (2016). David Sloan Wilson is trying to revive the idea of biological evolution to explain group selection, or multilevel selection, in society, and he argues on these grounds that selfishness beats altruism within single groups, but that altruistic groups beat selfish groups (Wilson and Wilson 2007). In an attempt to generalize core design principles for efficient resource management of common-pool resources (CPRs), Wilson et al. (2013) combine Ostrom's CPR framework with socio-biological principles (multilevel selection) for group formation.

Associated with the work of social philosopher, originally theologian, Bruno Latour (2005), ANT actually originated in research closely related to socio-biology. Collaborating with primatologist Shirley Strum (Strum and Latour 1987), Latour argued that humans distinguish themselves from other animals by anchoring their social relations in artifacts that are external to their own bodies. These artifacts include physical manufactured items as well as symbols, concepts, and words. Paradoxically, this distinction between humans and other animals has recently evolved into the doctrine of posthumanism, which denies that humans are in any way exceptional. The development occurred via an application of ANT, which holds that artifacts and nonhuman entities are all equally sources of agency, or "actants." Originally applied in support of an extreme version of social constructivism in which Latour argued that the discoveries of natural science were the result of specific alliances between scientists, their instruments, and their objects of study, ANT reduces all scientific truth to politics and other contingencies. In other words, there is no objective reality out there. This approach granted Latour a pivotal role in the so-called science wars between natural scientists and social constructivists (cf. Parsons 2003). Latour's position appears to be tantamount to not only a dismissal of the ontological assumptions of natural science, but also, by pursuing its radical empiricism, to the simultaneous rejection of the concept of society, a provocation aimed also at social science. ANT is thus difficult to fit into the pattern of scientific imperialism we have suggested. Although its extreme version of constructivism is clearly a challenge to natural science, it also challenges all attempts at theory building in social science. Moreover, Latour's endorsement of "the ontological turn" in anthropology and other social sciences suggests that he is best understood as a radical pluralist rather than a unificationist (see Fig. 1). This anomaly may be indicative of a contradiction within his approach, namely, between the ambition to encompass all knowledge production within a single theoretical framework, on one hand, and the professed respect for diverse ontologies, on the other.

Fig. 1. Scientific and societal implications of two approaches to interdisciplinarity.

\begin{tabular}{l}
$\begin{array}{l}\text { Interdisciplinary } \\
\text { approach }\end{array}$ \\
\hline Unificationism \\
implication
\end{tabular}

One of Latour's most influential, but also most problematic, claims is that the very distinction between nature and society, as he puts it, is misleading (Latour 1993). Although it is incontrovertible that social and natural features and forces are intertwined in most real-world phenomena, such as bodies, landscapes, technologies, and climate change, this does not justify abandonment of the analytical distinction between drivers deriving from pre- or nonsocial nature, e.g., thermodynamics, and human societies, e.g., markets.

\section{SCIENTIFIC AND SOCIETAL IMPLICATIONS OF TWO APPROACHES TO INTERDISCIPLINARITY}

Our examples illustrate, perhaps even demonstrate, a recurrent tendency among putatively interdisciplinary endeavors to result in scientific imperialism or other conspicuous failures to engage in constructive dialogue between the social and natural sciences. In this way, they bear witness to the fundamental impact of unificationism in subjects close to sustainability science and the kind of agonism, resulting from perceived imperialism, discussed by Krueger et al. (2016) with respect to water research. An exception perhaps is environmental history, where the position seems rather to be optimism without a preconceived plan. To summarize our argument, in Figure 1 we outline the relations between two fundamental ontological assumptions and the scientific implications of four different options opened up by these assumptions. The basic ontological issue is whether to assume that there are ontological differences that need to be taken into account (pluralism) or instead grant that all knowledge can be unified in a straightforward way into a single worldview (unificationism). The choice of approach to interdisciplinary collaboration, pluralism or unificationism, is of fundamental importance. Equally important for successful interdisciplinary 
collaboration are facts about, and properties of, the disciplines and domains involved. For instance, depending on whether the ontologies of the disciplines involved in interdisciplinary collaboration are in fact compatible or incompatible, pluralism and unificationism lead to different outcomes.

The situation resembles the familiar distinction between the two bad outcomes of rejecting truths and accepting falsehoods and the corresponding two good outcomes of accepting truths and rejecting falsehoods, a distinction fully worked out in terms of type I and type II errors in statistics (Neyman and Pearson 1928). For instance, although in basic science it is important not to posit a causal link when there is none, for a decision maker, and arguably also for many interdisciplinary scientists, it is often more important not to miss a causal link when there is one. Persson et al. (2018) modify this familiar distinction and research-strategic decision problem to catch two options in interdisciplinary decision making, Popperian optimism and Kuhnian pessimism, respectively.

A good outcome of pluralism is politically relevant, constructive dialogue in a situation where the ontologies of the collaborating disciplines are incompatible. A bad outcome of pluralism is politically irrelevant relativism in a situation where the ontologies of the collaborating disciplines are not incompatible. Both of these are potential consequences of pluralism, or more generally of the more cautious pessimistic Kuhnian attitude that we should not risk our disciplines by adapting their foundations in the face of interdisciplinary challenges.

One good outcome of unificationism is stakeholder relevance in a situation where the collaborating disciplines successfully integrate knowledge from two domains. Stakeholder relevance can be obtained in cases where the problem at hand is limited in scope and complexity. A bad outcome is inadequate understanding, which leads to one-dimensional decision making at the societal level, in a situation where the unificationist approach cannot integrate knowledge from more than one of the collaborating disciplines. Both of these are potential consequences of unificationism, or more generally of a more optimistic Popperian attitude that disciplines are administrative and historical entities that should not stand in the way of scientific progress.

One equivalent of failed Popperian optimism in Figure 1 would be to adopt the strategy of unificationists and proceed on the assumption that there are no ontological barriers to integration, when there in fact are, thus ending up in a position of unwarranted scientific imperialism. The same strategy, successfully applied, would be the kind of "legitimate" scientific imperialism that Mäki talks about, in the passage excerpted previously, where "there is unity in the world itself" (Mäki 2013:336). The successful result would be a unified framework. We acknowledge the existence of such cases in the literature, and they are often designed to model local, relatively isolated environments. An example is the application of Elinor Ostrom's general institutional framework for analyzing the sustainability of social-ecological systems (Ostrom 2009). Proceeding from prominent examples, such as the Maine lobster fisheries (Acheson and Gardner 2011) and wetland conservation in Kristianstad Vattenrike (Olsson et al. 2004, Hahn 2011), the framework has successfully been applied to a range of fisheries understood as commons around the world (Dietz et al.
2003). It is clear that stakeholder relevance can be a societal implication of unified frameworks. When the constraints of that framework are ignored, however, the framework reveals that it is geared to practical utility rather than genuinely interdisciplinary knowledge integration (Agrawal 2003). Examples of failures to respect such constraints include the absence of clearly defined boundaries of the resource system and the lack of appropriate institutions for organizing a congruence between appropriation rules and provision rules, collective decisions, effective monitoring of the resource and its use, sanctions for violation of the rules, conflict-resolution mechanisms, and recognition by higher level authorities.

We are afraid, however, that the eight illustrations might turn out to exemplify typical cases of unwarranted scientific imperialism. The recurrent societal implication is the risk of one-dimensional decision making. This risk can be a problem regardless of whether the "imperialist" project emanates from natural or social science. One-dimensional decision making is as likely a consequence, for example, of resilience theory and socio-biology as it is of environmental economics and environmental history. Admittedly, only time will tell whether scientific imperialism succeeds or not. This happens when reality reasserts itself somewhere down the line. We cannot conclude that the eight illustrations are imperialistic failures until then, scientifically speaking. However, they can be identified as societal failures before that. Onedimensional decision making now guided by an approach that will prove successful when further developed is not rational if the alternative involves relying on more pluralistic evidence.

A successful unificationist attempt may generate knowledge with considerable stakeholder relevance, but, given the undeniable differences between many natural and social phenomena, and between phenomena within these spheres, it cannot be expected that more than a few of our most well-thought-out unificationist attempts will lead to genuine interdisciplinary integration of entire disciplines and their domains of application. Models of CPR management rarely reveal general insights into the interaction of capitalist extractivism and ecology. It is therefore possible to be a Popperian optimist, without taking the wisdom of disciplines for granted, and be a pluralist at the same time. Perhaps this is what the example of environmental history illustrates. The Popperian optimist has no reason to take current theory very seriously and thus no reason to be an imperialist.

However, in those cases in which unificationism would work globally, pluralism involves a missed opportunity. Constructive dialogue is a good thing, but not as good as a unified framework. Moreover, there is an obvious risk that pluralists will sometimes find themselves in a position where all ontological claims are regarded as equally justified when, as a matter of fact, some of the claims are right and others wrong. In other words, pluralists might mistakenly side with ontological relativists. The societal implication is political irrelevance. An obvious example is the socalled ontological turn in anthropology, whose claim that different groups literally live in different worlds is difficult to reconcile with political positioning.

The desired outcome of pluralism is to establish constructive dialogue in cases where ontological unificationism would fail. The true strength of the pluralist strategy in comparison with unificationism is that we already know two things about the 
chances in Figure 1. We know that the chances of ending up in constructive dialogue and the chances of being forced to adopt ontological relativism are not the same. Even more importantly, we know that the probability that the pluralist will end up in constructive dialogue is greater than the probability that the unificationist will end up with a unified framework.

What, then, is advantageous about constructive dialogue, and what does it mean? Thorén and Persson (2013) argue that a powerful way of collaborating in an interdisciplinary way is through problem feeding. Problem feeding is a form of interdisciplinary exchange in which the central object of exchange is a problem, or set of problems, rather than, say, a concept, model, or theory. The basic idea is that problems occasionally arise within disciplines in which they cannot be easily solved. For example, our recognition of the seriousness of climate change, which was for a long time the exclusive domain of the natural sciences, has produced a wealth of problems that clearly fall within the purview of the social sciences. How can, and how should, we adapt to climate change? What is the best balance between mitigation and adaptation? What are the limits of adaptation (e.g., Sherwood and Huber 2010)? What are the social drivers of climate change? And so on.

Problem feeding may also serve to protect the ontology assumed by a discipline by essentially exporting an otherwise burdensome anomaly. This involves constraining the domain of the "exporting" discipline, to a degree anyway, but it also goes to show that interdisciplinary interaction sometimes serves to reduce intradisciplinary inconsistencies, perhaps at the expense of leaving interdisciplinary ones (Thorén and Persson 2013, Thorén 2015).

\section{CONCLUSIONS: TOWARD AN ALTERNATIVE DIALOGUE}

Gregory Bateson (1972) once suggested that a truly holistic understanding of human-environmental relations requires the (rare) capacity to grasp, simultaneously, the significance of the concepts of sacrament and entropy. It is indeed absolutely crucial to acknowledge the worlds of constructed human meanings, as well as the material universe with which they are intertwined, and, we would add, distinguish analytically between them. The interpenetration of social and natural aspects of reality is particularly obvious in issues pertaining to sustainability. Sustainability research thus demands familiarity with, and respect for, both kinds of factor and acknowledgement of how profoundly they can influence each other.

It will be obvious that we endorse the acknowledgement of ontological pluralism. We hope it will be equally apparent that we simultaneously reject the irrelevance of wholesale ontological relativism, instead advocating complex ways of articulating divergent ontological assumptions. This is not equivalent to pursuing unification, whether through scientific imperialism or by catering to the requirements of narrow practical utility. It means prioritizing interdisciplinary integration by recognizing, at one and the same time, the role of societal and cultural factors and presymbolic/nonhuman, biophysical conditions in accounting for sustainability issues. As we have indicated, none of the currently prominent eight interdisciplinary fields briefly reviewed in itself manages to provide, in a satisfactory way, such an integrated understanding of sustainability.
We can conclude by indicating examples of the kind of mutual respect between the social and natural sciences that will be crucial to constructive dialogue on sustainability, that is, the alternative dialogue we would like to propose in the absence of truly promising unificationist theories. Resilience theory will need to acknowledge the roles of power, money, and culture in generating unsustainable structures and human behavior, while PE will need to reckon with biophysical aspects of human-environmental relations. Environmental economics cannot possibly deal with sustainability issues without a basic grasp of thermodynamics and ecology, but ecological economics needs to respect the significance of market institutions and cultural definitions of utility and monetary exchange value. Environmental history would benefit from greater attention to the material, as opposed to ideational, aspects of the history of human-environmental relations, while historical ecology needs to give more consideration to culture and mentality. Socio-biology must refrain from reducing human society and culture to biology, but, equally, ANT must concede that objective, natural aspects of reality exist that cannot be reduced to politics and social construction. Only by building dialogues between such diametrically opposed fields can we hope to promote a general understanding of the predicaments of the so-called Anthropocene. Anthropogenic climate change is an empirical reality illuminated by earth system science, regardless of human constructions of reality, yet we must keep in mind that it is propelled by forces, such as money, power, and culture, that are the domain of the social sciences. It is a quintessential problem of the sort requiring truly interdisciplinary dialogue. There is room for unificationism but not for much imperialism within such an alternative dialogue. Unificationism can be about many things besides ontology: explanations, virtues, goals, methods, models, and kinds of representations. Problems that arise in one discipline might need to borrow any of these from the other or to export the problem to the other side in a bilateral problem-solving attempt.

Politically relevant constructive dialogue between social and natural sciences might begin by observing that the powerful modern discourses of economics and engineering, both invented at the heart of the British colonial empire in the early 19th century, manage to represent asymmetric global exchange and accumulation as unquestionable, "natural" processes. As Latour would no doubt agree, both fields refer to socio-natural phenomena, but they retain their political immunity by presenting themselves as concerned with either society or nature. Modernity, and the Anthropocene, is thus founded on the illusion that economic progress can be discussed in isolation from natural science, and, conversely, that technological progress is a matter of revealing "purified" truths of nature, sequestered from the asymmetric structures of world society. The challenge of the Anthropocene is therefore to fundamentally rethink the categories of economy and technology by fully acknowledging both the social and natural aspects of these socio-natural phenomena.

${ }^{[1]}$ This helps to bring out an important aspect of plurality and pluralism. Deep and extensive plurality and differentiation in science is usually taken for granted; the philosophically contentious issue revolves around normative questions, questions about whether plurality with respect to this or that is acceptable 
or even desirable (Mäki 1997). Many pluralists believe that local unification is quite acceptable and argue that it is an empirical matter whether plurality or unification ultimately persists (Kellert et al. 2006).

\section{AUTHOR CONTRIBUTIONS}

Alf Hornborg, Johannes Persson, and Lennart Olsson conceived the idea and designed the study; Alf Hornborg, Johannes Persson, Lennart Olsson, and Henrik Thorén coauthored the first version of the manuscript; Johannes Persson revised the first version of the manuscript; and Henrik Thorén contributed to the revised version.

Responses to this article can be read online at: http://www.ecologyandsociety.org/issues/responses. php/10498

\section{Acknowledgments:}

We are grateful to colleagues in the LUCID consortium, and Eric Clark in particular, who contributed with comments on earlier drafts of this article. Funding: The research has been funded by the following research projects: Swedish Research Council Formas Linnaeus grant LUCID, Lund University Centre of Excellence for integration of Social and Natural Dimensions of Sustainability (259-2008-1718; to A.H., J.P., L.O., and H.T.), and the Swedish Foundation for Humanities and Social Sciences program VBE, Science and Proven Experience (M14-0138:1; to J.P.). Competing interests: The authors declare that they have no competing interests.
\end{abstract}

\section{LITERATURE CITED}

Acheson, J., and R. Gardner. 2011. The evolution of the Maine lobster V-notch practice: cooperation in a prisoner's dilemma game. Ecology and Society 16(1):41. http://dx.doi.org/10.5751/ ES-04004-160141

Agrawal, A. 2003. Sustainable governance of common-pool resources: context, methods, and politics. Annual Review of Anthropology 32:243-262. http://dx.doi.org/10.1146/annurev. anthro.32.061002.093112

Alcock, J. 2017. The behavioral sciences and sociobiology: a Darwinian approach. Pages 37-59 in R. Delisle, editors. The Darwinian tradition in context. Springer, Cham, Switzerland. http://dx.doi.org/10.1007/978-3-319-69123-7 3

Alvergne, A., and V. Lummaa. 2014. Ecological variation in wealth-fertility relationships in Mongolia: the 'central theoretical problem of sociobiology' not a problem after all? Proceedings of the Royal Society B: Biological Sciences. 281(1796):20141733.

Ayres, R. 2016. Energy, complexity and wealth maximization. Springer, New York, New York, USA. http://dx.doi. org/10.1007/978-3-319-30545-5

Balée, W., and C. L. Erickson, editors. 2006. Time and complexity in historical ecology: studies in the neotropical lowlands. Columbia University Press, New York, New York, USA. http://dx.doi. org/10.7312/bale13562
Bammer, G. 2013. Disciplining interdisciplinarity: integration and implementation sciences for researching complex real-world problems. Australian National University Press, Canberra, Australian Capital Territory, Australia. http://dx.doi.org/10.26530/ OAPEN 459901

Bateson, G. 1972. Steps to an ecology of mind. Paladin, Frogmore, UK.

Berkes, F., and C. Folke, editors. 1998. Linking social and ecological systems: management practices and social mechanisms for building resilience. Cambridge University Press, Cambridge, UK.

Bhaskar, R. A. 1997/1975. A realist theory of science. Second edition [original work published in 1975]. Verso, London, UK.

Blaikie, P. 2008. Epilogue: towards a future for political ecology that works. Geoforum 39(2):765-772. http://dx.doi.org/10.1016/j. geoforum.2007.07.004

Bryant, R. L., and S. Bailey. 1997. Third world political ecology. Routledge, London, UK.

Cat, J. 2017. The unity of science. In E. N. Zalta, editor. The Stanford Encyclopedia of Philosophy. Fall 2017 edition. [online] URL: https://plato.stanford.edu/archives/fall2017/entries/scientific$\underline{\text { unity/>. }}$

Costanza, R. 1980. Embodied energy and economic valuation. Science 210(4475):1219-1224. http://dx.doi.org/10.1126/ science. 210.4475 .1219

Costanza, R., R. d'Arge, R. de Groot, S. Farber, M. Grasso, B. Hannon, K. Limburg, S. Naeem, R. V. O’Neill, J. Paruelo, R. G. Raskin, P. Sutton, and M. van den Belt. 1997. The value of the world's ecosystem services and natural capital. Nature 387:253-260. http://dx.doi.org/10.1038/387253a0

Crumley, C. L., editor. 1994. Historical ecology: cultural knowledge and changing landscapes. School of American Research, Santa Fe, New Mexico, USA.

Dietz, T., E. Ostrom, and P. C. Stern. 2003. The struggle to govern the commons. Science 302:1907-1912. http://dx.doi.org/10.1126/ $\underline{\text { science. } 1091015}$

Dray, W. 1957. Laws and explanation in history. Oxford University Press, Oxford, UK.

Dupré, J. 2001. Human nature on the limits of science. Oxford University Press, Oxford, UK. http://dx.doi.org/10.1093/019924$\underline{8060.001 .0001}$

Fischhoff, B. 2016. Conditions for sustainability science. Environment: Science and Policy for Sustainable Development 58 (1):20-24. http://dx.doi.org/10.1080/00139157.2016.1112168

Georgescu-Roegen, N. 1971. The entropy law and the economic process. Harvard University Press, Cambridge, Massachusetts, USA. http://dx.doi.org/10.4159/harvard.9780674281653

Gould, S. J., and Lewontin, R. C. 1979. The spandrels of San Marco and the Panglossian paradigm: a critique of the adaptationist programme. Proceedings of the Royal Society B: Biological Sciences 205(1161):581-598. https://doi.org/10.1098/ rspb.1979.0086 
Gunderson, L. H., and C. S. Holling, editors. 2002. Panarchy: understanding transformation in human and natural systems. Island, Washington, D.C., USA.

Hacking, I. 1983. Representing and intervening: introductory topics in the philosophy of natural science. Cambridge University Press, Cambridge, UK. http://dx.doi.org/10.1017/CBO9780511814563

Hahn, T. 2011. Self-organized governance networks for ecosystem management: who is accountable? Ecology and Society 16(2):18. http://dx.doi.org/10.5751/ES-04043-160218

Hall, C. A. S., and K. A. Klitgaard. 2011. Energy and the wealth of nations: understanding the biophysical economy. Springer, New York, New York, USA.

Hansson, B. 1999. Interdisciplinarity: for what purpose? Policy Sciences 32(4):339-343. https://doi.org/10.1023/A:1004718320735

Hayek, F. A. v. 1942. Scientism and the study of society. Part I. Economica 9(35):267-291. http://dx.doi.org/10.2307/2549540

Hempel, C. G. 1965. Aspects of scientific explanation and other essays in the philosophy of science. Free, New York, New York, USA.

Hornborg, A. 2009. Zero-sum world: challenges in conceptualizing environmental load displacement and ecologically unequal exchange in the world-system. International Journal of Comparative Sociology 50(3-4):237-262. http://dx.doi. org/10.1177/0020715209105141

Hornborg, A. 2010. Toward a truly global environmental history: a review article. Review: A Journal of the Fernand Braudel Center 33(4):295-323.

Hornborg, A. 2013. Global ecology and unequal exchange: fetishism in a zero-sum world. Revised paperback version. Routledge, London, UK. http://dx.doi.org/10.4324/9780203806890

Hornborg, A. 2017. Artifacts have consequences, not agency: toward a critical theory of global environmental history. European Journal of Social Theory 20(1):95-110. http://dx.doi. org/10.1177/1368431016640536

Hornborg, A., J. R. McNeill, and J. Martinez-Alier, editors. 2007. Rethinking environmental history: world-system history and global environmental change. AltaMira, Lanham, Maryland, USA.

Hughes, J. D. 2001. An environmental history of the world: humankind's changing role in the community of life. Routledge, London, UK.

Jerneck, A., L. Olsson, B. Ness, S. Anderberg, M. Baier, E. Clark, T. Hickler, A. Hornborg, A. Kronsell, E. Lövbrand, and J. Persson. 2011. Structuring sustainability science. Sustainability Science 6(1):69-82. http://dx.doi.org/10.1007/s11625-010-0117-X

Kellert, S., H. Longino, and K. Waters. 2006. Introduction: the pluralist stance. Pages vii-xxix in S. Kellert, H. Longino, and K. Waters, editors. Scientific pluralism. Volume 19 of Minnesota Studies in the Philosophy of Science. University of Minnesota Press, Minnesota, Minneapolis, USA.

Klein, J. T. 1990. Interdisciplinarity: history, theory, and practice. Wayne State University Press, Detroit, Michigan, USA.
Krueger, T., C. Maynard, G. Carr, A. Bruns, E. N. Mueller, and S. Lane. 2016. A transdisciplinary account of water research. WIREs Water 3:369-389. http://dx.doi.org/10.1002/wat2.1132

Kuorikoski, J., and A. Lehtinen. 2010. Economics imperialism and solution concepts in political science. Philosophy of the Social Sciences 40(3):347-374. http://dx.doi.org/10.1177/0048393109341452

Latour, B. 1993. We have never been modern. Harvard University Press, Cambridge, Massachusetts, USA.

Latour, B. 2005. Reassembling the social: an introduction to actornetwork-theory. Oxford University Press, Oxford, UK.

Ludwig, D., D. D. Jones, and C. S. Holling. 1978. Qualitative analysis of insect outbreak systems: the spruce budworm and forest. Journal of Animal Ecology 47(1):315-332. http://dx.doi. org/10.2307/3939

Mäki, U. 1997. The one world and the many theories. Pages 37-47 in A. Salanti and E. Screpanti, editors. Pluralism in economics: new perspectives in history and methodology. Edward Elgar, Aldershot, UK.

Mäki, U. 2009. Economics imperialism: concept and constraints. Philosophy of the Social Sciences 39(3):351-380. http://dx.doi. org/10.1177/0048393108319023

Mäki, U. 2013. Scientific imperialism: difficulties in definition, identification, and assessment. International Studies in the Philosophy of Science 27:325-339. http://dx.doi.org/10.1080/026$\underline{98595.2013 .825496}$

Martinez-Alier, J. 1987. Ecological economics: energy, environment and society. Blackwell, Oxford, UK.

McNeill, J. R. 2000. Something new under the sun: an environmental history of the twentieth-century world. W. W. Norton, New York, New York, USA.

McNeill, J. R., and P. Engelke. 2016. The great acceleration: an environmental history of the Anthropocene since 1945. Belknap, Cambridge, Massachusetts, USA. http://dx.doi.org/10.4159/978$\underline{0674970731}$

Midgley, M. 1984a. Reductivism, fatalism and sociobiology. Journal of Applied Philosophy 1(1):107-114. http://dx.doi. org/10.1111/j.1468-5930.1984.tb00190.x

Midgley, M. 1984b. Sociobiology. Journal of Medical Ethics 10:158-160. http://dx.doi.org/10.1136/jme.10.3.158

Mill, J. S. 2002/1843. A system of logic. Reprint of 1891 edition [original work published in 1843]. University Press of the Pacific, Honolulu, Hawaii, USA.

Neyman, J., and E. S. Pearson. 1928. On the use and interpretation of certain test criteria for purposes of statistical inference. Part I. Biometrika 20A(1/2):175-240. http://dx.doi.org/10.2307/2331945

Odum, H. T. 1971. Environment, power, and society. WileyInterscience, New York, New York, USA.

Odum, H. T. 1988. Self-organization, transformity, and information. Science 242:1132-1139. http://dx.doi.org/10.1126/ science. 242.4882 .1132 
Olsson, P., C. Folke, and T. Hahn. 2004. Social-ecological transformation for ecosystem management: the development of adaptive co-management of a wetland landscape in southern Sweden. Ecology and Society 9(4):2. http://dx.doi.org/10.5751/ ES-00683-090402

Olsson, L., and A. Jerneck. 2018. Social fields and natural systems: integrating knowledge about society and nature. Ecology and Society 23(3):26. http://dx.doi.org/10.5751/ES-10333-230326

Olsson, L., A. Jerneck, H. Thoren, J. Persson, and D. O’Byrne. 2015. Why resilience is unappealing to social science: theoretical and empirical investigations of the scientific use of resilience. Science Advances 1(4):e1400217. http://dx.doi.org/10.1126/ sciadv. 1400217

O'Neill, J. 2004. Ecological economics and the politics of knowledge: the debate between Hayek and Neurath. Cambridge Journal of Economics 28(3):431-447. https://doi.org/10.1093/ cje/28.3.431

O'Rourke, M., S. Crowley, and S. Gonnerman. 2016. On the nature of cross-disciplinary integration: a philosophical framework. Studies in History and Philosophy of Biological and Biomedical Sciences 56:62-70. http://dx.doi.org/10.1016/j. shpsc.2015.10.003

Ostrom, E. 2009. A general framework for analyzing sustainability of social-ecological systems. Science 325:419-422. $\underline{\text { http://dx.doi.org/10.1126/science.1172133 }}$

Parsons, K., editor. 2003. The science wars: debating scientific knowledge and technology. Prometheus Books, Amherst, New York, USA.

Persson, J. 2010. Misconceptions of positivism and five unnecessary science theoretic mistakes they bring in their train. International Journal of Nursing Studies 47(5):651-661. http://dx. doi.org/10.1016/j.ijnurstu.2009.12.009

Persson, J., H. Thorén, and L. Olsson. 2018. The interdisciplinary decision problem: Popperian optimism and Kuhnian pessimism in forestry. Ecology and Society 23(3):40. http://dx.doi. org/10.5751/ES-10401-230340

Popper, K. 1952. The open society and its enemies. Second edition. Routledge, London, UK.

Radkau, J. 2008. Nature and power: a global history of the environment. Cambridge University Press, Cambridge, UK.

Redman, C. L. 1999. Human impact on ancient environments. University of Arizona Press, Tucson, Arizona, USA.

Richards, J. F. 2003. The unending frontier: an environmental history of the early modern world. University of California Press, Berkeley, California, USA.

Robbins, P. 2004. Political ecology: a critical introduction. Blackwell, Oxford, UK.

Sahlins, M. D. 1977. The use and abuse of biology: an anthropological critique of sociobiology. University of Michigan Press, Ann Arbor, Michigan, USA. http://dx.doi.org/10.3998/ mpub.20259
Seidl, R., and R. Barthel. 2017. Linking scientific disciplines: hydrology and social sciences. Journal of Hydrology 550:441-452. http://dx.doi.org/10.1016/j.jhydrol.2017.05.008

Shadish, W. R. 1995. Philosophy of science and the quantitativequalitative debates: thirteen common errors. Evaluation and Program Planning 18(1):63-75. http://dx.doi.org/10.1016/0149-7189 (94)00050-8

Sherwood, S. C., and M. Huber. 2010. An adaptability limit to climate change due to heat stress. Proceedings of the National Academy of Sciences of the United States of America 107 (21):9552-9555. http://dx.doi.org/10.1073/pnas.0913352107

Strum, S. S., and B. Latour. 1987. Redefining the social link: from baboons to humans. Social Science Information 26:783-802. http://dx.doi.org/10.1177/053901887026004004

Thorén, H. 2015. The hammer and the nail. Dissertation. Lund University, Lund, Sweden.

Thorén, H., and J. Persson. 2013. The philosophy of interdisciplinarity: sustainability science and problem-feeding. Journal for General Philosophy of Science 44(2):337-355. http:// dx.doi.org/10.1007/s10838-013-9233-5

Vayda, A. P., and B. B. Walters. 1999. Against political ecology. Human Ecology 27(1):167-179. http://dx.doi.org/10.1023/ A:1018713502547

von Uexküll, J. 2010. A foray into the worlds of animals and humans: with a theory of meaning. University of Minnesota Press, Minneapolis, Minnesota, USA.

Vreja, L. O., S. Balan, and L. C. Bosca. 2016. An evolutionary perspective on toxic leadership. Management and Economics Review 1(2):217-228.

Walker, J., and M. Cooper. 2011. Genealogies of resilience: from systems ecology to the political economy of crisis adaptation. Security Dialogue 42(2):143-160. http://dx.doi.org/10.1177/0967$\underline{010611399616}$

Walker, B., and D. Salt. 2012. Resilience thinking: sustaining ecosystems and people in a changing world. Island, Washington, D.C., USA.

Watts, M. J. 2015. Now and then: the origins of political ecology and the rebirth of adaptation as a form of thought. Pages 19-50 in T. Perreault, G. Bridge, and J. McCarthy, editors. The Routledge handbook of political ecology. Routledge, London, UK.

Wilson, E. O. 1975. Sociobiology: the new synthesis. Harvard University Press, Cambridge, Massachusetts, USA.

Wilson, D. S., E. Ostrom, and M. E. Cox. 2013. Generalizing the core design principles for the efficacy of groups. Journal of Economic Behavior \& Organization 90:S21-S32. http://dx.doi. org/10.1016/j.jebo.2012.12.010

Wilson, D. S., and E. O. Wilson. 2007. Rethinking the theoretical foundation of sociobiology. Quarterly Review of Biology 82 (4):327-348. http://dx.doi.org/10.1086/522809

Wolman, M. G. 1977. Interdisciplinary education: a continuing experiment. Science 198(4319):800-804. http://dx.doi.org/10.1126/ science.198.4319.800 